medical officers, and an assistant surgeon. The medical officers attend to medical, surgical, or obstetric cases indiscriminately. We should have expected, at least, that they would have evoluted into physicians and surgeons. The assistant surgeon has to visit patients at their own homes, for which he receives a salary.

We confess to our surprise at finding that there is no resident house-surgeon. Surely a hospital of this size, where important operations take place, and the emergencies and accidents of a large town are treated, should have a resident house-surgeon. It was pointed out to us that there is telephonic communication to the private houses of the staff, and that the matron makes an excellent house-surgeon. Still, there can be no question but that there are certain classes of cases where the delay of getting a doctor from a distance is fatal to the patient. To mention a few such instances, cases

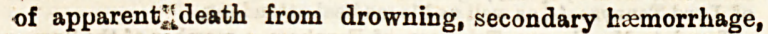
internal hæ. morrhage, urgent tracheotomies, "drunk or dying cases."

The nursing staff consists of a matron, head nurse, and four probationers. It is proposed to affiliate a nursing institute with the hospital. The hospital w i 11 train the probationers, who, when trained, will be sent out private nursing. We understand that there is no such institution in the town.

Since the opening of the ne w hospital the number of in-patients has doubled, being now 208 annually. About 2,000 out - patients are also attended to.

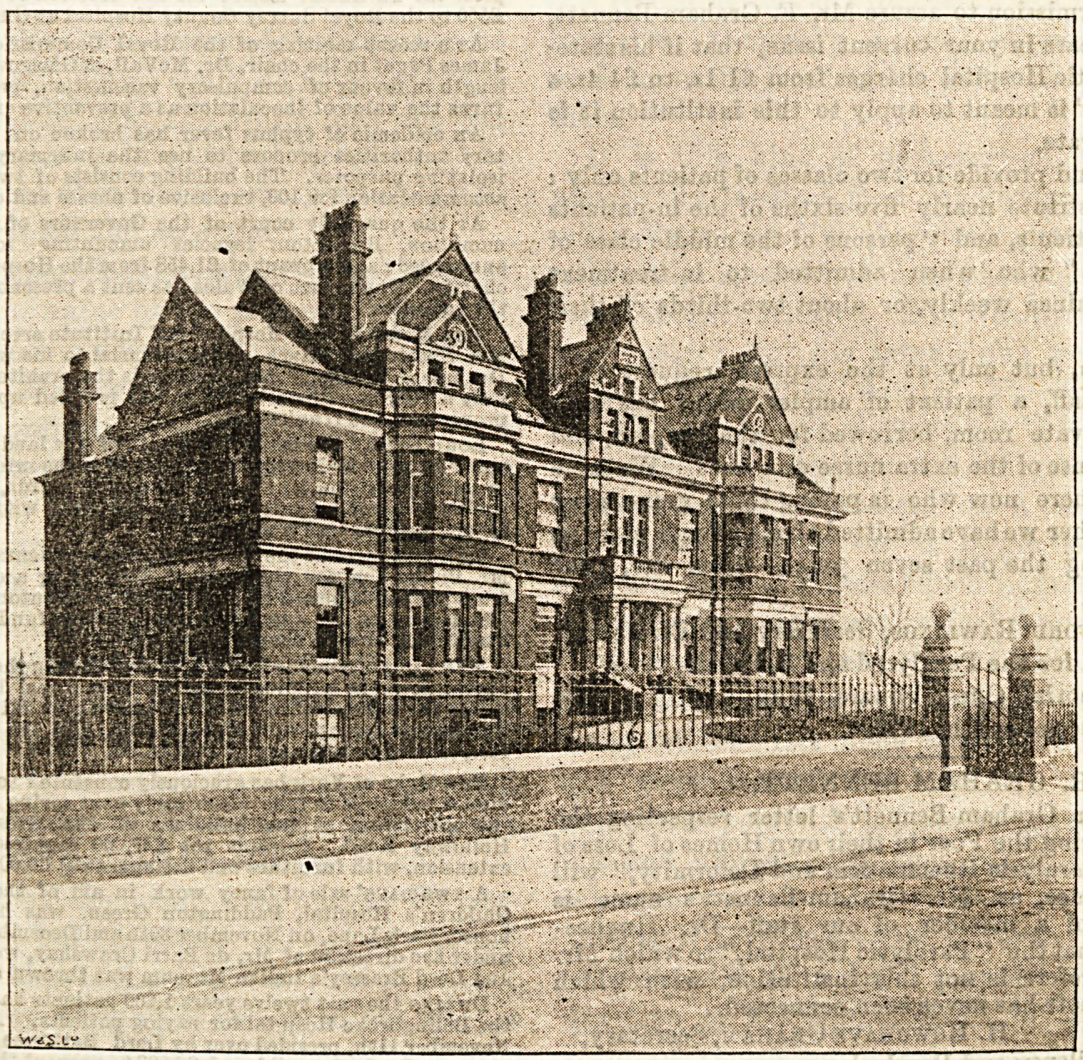

Victoria Hospital, Folkestone.

\section{NEW HOSPITALS.}

ROYAL EYE HOSPITAL, SOUTHWARK.

The opening of the new premises of the Royal Eye Hospital, Southwark, by H.R.H. the Duke of York, is fixed for one p.m. on Thursday the 15th inst. This is likely to prove a memorable occasion in south London, which, though a district not less poverty stricken than the Esst-end, is one which until the foundation-stone of this hospital was laid by H.R.H. the Prince of Wales in 1890 , had hardly any recollection of a Royal visit. The coming ceremonial, marking as it will the commencement of public life by the Duke of York in his present exalted position, and as the first Royal ceremonial of the year, excites peculiar enthusiasm. This will be intensified by a knowledge of the exceptionally special care bestowed upon all details in the de. sign and fitting of this hospital. Sir Joseph Lister, Bart., has recently critically inspected the new premises throughout, and expressed his aston. ishment and gratification that London now possesses a hospital in which such conspicuous attention $\mathrm{h}$ a $\mathrm{s}$ been given to all the lessons revealed by the light which this parent and pro. phet of antiseptic surgery has shed for the benefit of suf. fering humanity, and the wor ld-wide credic of British surgical research. His approval has taken lasting form, insomuch that Sir Joseph Lister has now cheerfully ac. cepted, as an esteemed hon-
That the new building has been opened free of debt speaks well for the business capacity of the committee of management. We understand, however, that the maintenance funds are low, but we cannot think that the Folkestone public, if properly approached, will long allow this to be the case.

The defects which we have pointed out are perfectly remediable, and, though they are such as commonly occur at first in the organization of a country hospital we feel sure that in such an advancing watering-place they will not have a very long lease.

The picture of the hospital given above is from a photo. graph by Messrs. Lambert, Weston, and Sons.

As addition has been made to Australian periodical literature by the launching on the world of the Antipodean, the object of which is to form "a literary link between the mother country and those of her children who are beyond the seas." our, the invitation of the authorities to become consulting surgeon to the institution, which, though a purely honorary office, is felt to be far from an undistinguished one in connection with a hospital which is the very embodiment of all that the Victorian era has taught regarding hospital construction.

The uniform and scrupulous practice of this hospital's authorities in not spending, other than for the relief of the suffering poor, any of the money entrusted to them, is now receiving tangible evidence of approval, for unsolicited, but most welcome, contributions are reaching the Chairman of the Robuilding Sub-Committee, so that he hopes to have in hand sufficient to defray the expenses of the opening ceremonial without stinting in anything which can enhance the success, interest, and instructiveness of the cccasion.

Arrangements are being made to comfortably seat a large 
company, who will assemble to the music of the Royal Marine Artillery Band. The special features of the hospital will be demonstrated by the aid of a powerful optical lantern, as without this device the many useful lessons which this hospital illustrates would be lost to the majority. The Reception Committee, which will be presided over by H.R.H. the Duke of Cambridge, as chairman, and Admiral of the Fleet, the Hon. Sir Harry Keppel, as vice-chairman, includes, among other notable and representative persons, the following : The Right Hon. the Lord Mayor, Lord Bishop of Rochester, Earl Kilmorey, Bishop Suffragan of Southwark, Archbishop of Westminster, Sir Thomas Lucas, Burt., Sir Joseph Fayrer, K.C.S.I., M.D., and Sir Richard Wyatt.

\section{HOSPITAL OPINION.}

[Contributions critical, snggestive, controversial, and technical are in. vited for this column, which is open to everyone who has anything to gay that is of practicalvalue and interest.]

PAYING PATIENTS AT SPECIAL HOSPITALS.

I beg your permission to assure Mr. F. Graham.Bennett, whose letter appears in your current issue, that if his statethat " the Paralytic Hospital charges from $£ 1$ 1s. to $£ 44$ s. a week to patients " is meant to apply to this institution it is singularly inaccurate.

We recognize and provide for two classe of patients only : the free, who constitute nearly five-sixths of the in-patients and all the out-patients, and "persons of the middle class of straitened means" who when admitted to in-treatment contribute one guinea weekly, or about two-thirds of their actual cost.

Now and again, but only at the express request of a member of the staff, a patient of ampler means has been admitted to a private room, borrowed for the purpose, and has paid the expense of the extra nurse or nurses. We have one such patient here now who is paying three guineas per week, and altogether we have admitted about twenty patients of this class during the past seven years.-I am, Sir, your obedient Servant,

B. Burford Rawlings, Secretary and Director. National Hospital for the Paralysed and Epileptic,

Albany Memorial, Queen Square, W.C., December 5th, 1892.

MR. GRA $\overline{\text { HAM-BENNETT. }}$

Referring to Mr. Graham.Bennett's letter respecting the "Hospital for Curing the Poor in their own Homes of Loss of Movement from Paralysis Rheumatism and Deformity," will you allow me space, as Mr. Graham.Bennett's name is rather like that of a member of our staff-Dr. HughesBennett-to say that the "Paralytic Hospital," to which Mr. Graham.Bennett refers is not this institution, with which Mr. Graham.Bennett has never been connected.

H. Howgrave GrahaM, Secretary,

Hospital for Epilepsy and Paralysis,

32, Portland Terrace, Regent's Park.

\section{NEW DRUGS, APPLIANCES, AND THINGS MEDICAL.}

RESTRAINT OR REMOVAL JACKET FOR INSANE PATIENTS.

This jacket is effective and comfortable, but is too elaborate and unnecessarily formidable in appearance. Though restraint should certainly be used when it is required, still the garment employed should suggest the idea as little as possible. The jacket would be more easily put on if made to fasten behind, and such a harness-like arrangement of straps and buckles might be avoided, and, indeed, is not needed. The method of disposing of the arms is good. It would be a useful article for relieving officers who have to remove an excited patient to the asylum. It would give the patient the minimum of discomfort, and beneath a mackintosh would be quite unnoticed. The jackets are to be procured from Messrs. Pocock Brothers, 235, Southwark Bridge Road. The price complete with locked buckle and straps, is $35 \%$.

\section{SCRAPS AND GLEANINGS.} TwELvE cases of small.pox were reported last week to the Medical
Officer of Health for Islington.

A ratge Kosmic Fête is to take place in Dablin in May, 1893, in aid of the brilding fund of the Oity of Dablin Hospital.

Mrs. Fearnsides has sent a farther donation of $£ 250$ to the Irish Distressed Ladies' Fund, making a total of $£ 1,000$.

A WonkIna CoMmITrex has just been elected to carry on the necessary details connected with the building of the new Sonthport Infirmary.

THe return of the Registrar-General for Scotland states that in the country during the three months ending with S apt

Prince Henny of Batten berg has promised to preside at the fortyinth anniversary dinner of the German Hospital, which will take eighth anniversary dinner of the German Hospital, which

THE annual court of the Seamen's Hospital is announced to be THE annual court of the Seamen's Hospital is announced to be held on February 1st, 1893. The Lord Major has consented to

Dr. Whitine, who attended the late Lord Tennyson for many years when the Poet Laureate was at Blackdown. died saddenly on Monday 21:t inst. from apoplexy, aged 63. Dr. Whiting was a personal friend of Lord Tennyso a's, as well as his medical attendant.

The late Mr. G orge Trimmer, of Farnham, a member of the Surrey Oonnty Oouncil, has left $£ 15,000$ for the endowment of a cottage hos. $£ 500$ to the Royal Surrey Oounty Hospital at Guildford.

AT a recent meeting of the Royal Oommission on Vaccination, Sir James Paget in the chair, Dr. McVail, of Glasgow, sp pke at considerable tarns the value of inoculation as a preventive of small-pox.

Ax epidemic of typhas fever has broken out in Dandee. The sani. tary anthorities propose to use the infirmary at the Barracks for isolating purposes. The building consists of two storeys, and contains accommodation for 100 , exclusive of nurses and other attendants.

$\Delta T$ the quarterly court of the Governors of the Hospital for Oonsumption, Bro npton, legacies amounting to nearly $£ 5,000$ were charity. The Prince of Wales has sent a present of wine for the ase of the patient 3 .

THE Model Village Hospital and Institute erected at Almondsbury by THE Mode Village Hos a a memorial to his wife, was opened by the
Mr. Shotto Vere Hare. as a mestes of Rutland. Mr. Ponting is the architect. The hospital is not only a very handsome building, bat is fitted up with every modern im. provement and requirement.

LOND DERBY has made a free gift of the land for the site of the pro. posed Ormskirk Oottage Hospital. It is the watention of the Oommittee to make provision for \& ix beds first (two wards, three beds in each), as well as two gmall wards for special purposes, with overy accommodation for the medical staff and nurses.

THE Treasurer of the British Home for Incurables has received fron Mr. Pirder Simpson the sum of $\$ 250$, being a donstion sent by him from the funds placed at his disposal as executor of the late Mrs. El za Holm. (and to be applied to tho balding fand of the new Home at Streatham, now'in course of erection.

MANY improvements havo been madeduring the year in the wards and throughout the bailding of the Stirling Royal Infirmary. The raport states the number of in.patients to have beea 231 and ont-patients 1,734 . The income amounted to $£ 1,0029 \%$. 4d., and the expenditare to $£ 1,068$. The income amounted to $£$ leaving a deficiency of $£ 66$ 3s. $8 \mathrm{~d}$.

THE Duke of York has graciously consented to preside at a festival dinner, which is to take nlace early next spring in aid of the funds for the completion of the buildings of the Great Northern Hospital, Holloway Road. Towards the $£ 27,000$ required for the cost of the extension, with furnitare and fittings, only $£ 8,000$ has been promised.

A TWO-DAYS sale of faney work in aid of the extension fund of the Ohildren's Hospital, Paddington Green, wes held at Lord Brassey's honse, Park Lane, on November 30th and December 1st. Short concerts, under the direction of Mr. de Barri Orawshay, were given at intervals,
and Lord Brassey's Indian Museum was thrown open to the visitors.

DURING the past twelve years 1,200 patients have bsen received into the Boling broke Hosp tal for paying patients. At a meeting held on November 11th, presided over hy Lord Battersea, it was agreed to raise at once a fund, if possible, of $£ 2,(00$ to prevent the closing of so usefal an institation, which anfortunately at the present time is in fi aancial

AT t' $\theta$ annual meeting of the Portsmonth Eye and Ear Infirmary, the Major said that the new out patients' department had been completed thanks largely to an anonymous gift of $£ 1000$, but there was still a debt on the building. The balance-sheet showed the expenditure to have been $£ 2971 \mathrm{~s}$. 6d, , and the receipts $\$ 247$ 1s. 10d., leaving a deficiency of $£ 49$ 7s. 8d.

THe twenty-sixth annual report of the Reigate and Redhill Oottage Hospital shows that 186 cases came under treatment during the year. The average duration of each case was 20 days. Oertain necessary sanitary and other works in connection with the hospital hava boen carriod out,

Hrn Royal Hiqhress Princess Mary Adelaide of Teck opened a bizaar in aid of the Frfield Oottage Hospital, on Sita.day, the 19th inst. Th bazaar was organized with a viow to defray the expenses incurred in adding a new ward containing threo beds and the nos apartments in commemoration of the Jabilee year. It is 300 years since Fnfield received a visit from Royalty.

THE Governors of Addenbroke's Hospital, Oambridgeshire, have decided, upon the advice of $\mathrm{Mr}$. Rogers Field, to reconstruct the entir drainage system of the hospital. This will cost between $\$ 2,000$ and \&3,000, and as they have not the necessary funds to carry out this work, the Oommittee makes a special sppeal to the prblic for assistance, in order that trey may not be obliged, otherwise, to realise $80 \mathrm{mo}$ of the invested capital and cartail the income. 